\title{
Comparative evaluation of central venous pressure and sonographic inferior vena cava variability in assessing fluid responsiveness in septic shock
}

\author{
Manjri Garg, Jyotsna Sen ${ }^{1}$, Sandeep Goyal, Dhruva Chaudhry²
}

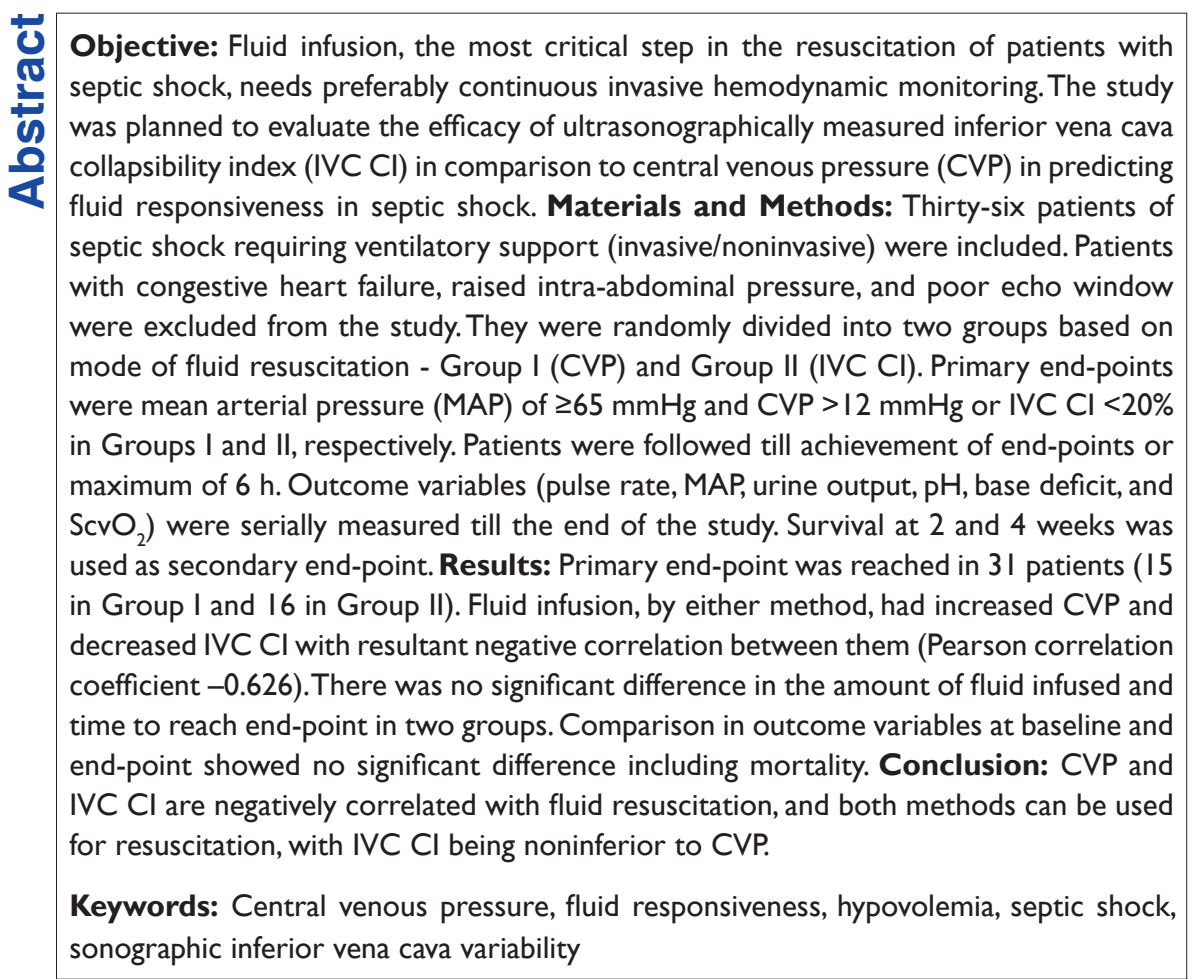

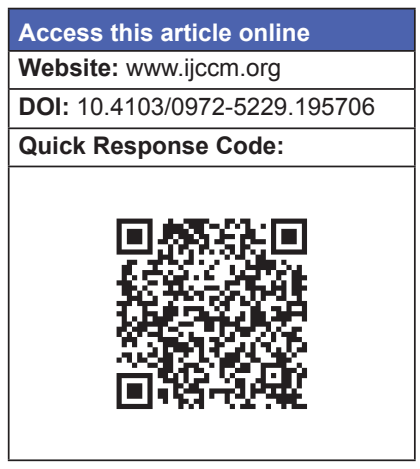

\section{Introduction}

Septic shock is a complex interplay of microbial and host defense system (cytokine storm), leading to capillary damage resulting into edema and hypotension. Fluid therapy corrects hypovolemia, improves microcirculation, modulates inflammation, and decreases the need for vasoactive agents. ${ }^{[1-4]}$ However,

\section{From:}

Departments of Medicine, ${ }^{1}$ Radiodiagnosis and ${ }^{2}$ Pulmonary and Critical Care Medicine, Pt. B.D. Sharma University of Health Sciences, Rohtak, Haryana, India

Correspondence:

Dr. Dhruva Chaudhry, 4/7J, Medical Enclave, PGIMS Campus,

Rohtak - 124001 Haryana, India.

E-mail: dhruvachaudhry@yahoo.co.in fluid acts as a double-edged sword as excessive fluid impairs diffusion at the cellular level and has been associated with increased mortality with acute respiratory distress syndrome net cohort demonstrating a positive association between cumulative fluid balance

This is an open access article distributed under the terms of the Creative Commons Attribution-NonCommercial-ShareAlike 3.0 License, which allows others to remix, tweak, and build upon the work non-commercially, as long as the author is credited and the new creations are licensed under the identical terms.

For reprints contact: reprints@ medknow.com

How to cite this article: Garg M, Sen J, Goyal S, Chaudhry D. Comparative evaluation of central venous pressure and sonographic inferior vena cava variability in assessing fluid responsiveness in septic shock. Indian J Crit Care Med 2016;20:708-13. 
and mortality. ${ }^{[5,6]}$ Fluid needs to be used judiciously as a drug in these cases, and intensivists need to have a regular watch over fluid balance of patient. Different types of shock have different pathophysiology, which can be unraveled by different patterns of combination of hemodynamic variables and can totally modify treatment strategy. Hemodynamic monitoring helps speed up treatment decisions and also assess response to them.

Till date, no parameter is ideal, and therefore, the inference needs to be drawn in clinical context. Central venous pressure (CVP), a traditional guide to fluid therapy, needs an invasive procedure to measure the pressure of right atrium which is being used as a surrogate for volume of left ventricle. ${ }^{[7]}$ Its value is altered by intrathoracic pressures, left and right ventricular contractility and may affect the assessment of intravascular volume. ${ }^{[8]}$

With more emphasis on noninvasive tools, nowadays, more and more simple methods are being developed for fluid assessment. One of them has been the change in inferior vena cava (IVC) diameter with respiration which has shown promising results as a guide to fluid therapy in various other studies. ${ }^{[9-13]}$ However, IVC collapsibility index (IVC CI) is also affected by intrathoracic pressures and right heart dysfunction similar to CVP. Marked inter-rater variability and lack of expertise in carrying out ultrasonographic (USG) IVC assessment further add to drawbacks of this method. ${ }^{[14]}$ Studies have shown an increase in CVP and decrease in IVC collapsibility with fluid infusion. Correlating these two methods, workers have also shown a negative correlation with fluid infusion, however, with certain limitations. ${ }^{[12,15]}$ Keeping these things in mind, the study was planned to evaluate the efficacy of ultrasonographically measured IVC variability and to find correlation, if any, of same with CVP in predicting fluid responsiveness in patients with septic shock.

\section{Materials and Methods}

This prospective, randomized study was carried out in the Intensive Care Unit (ICU) of our institute and the Institutional Review Board approved the study protocol. Selection of patients was done from the emergency department, medical and surgical wards. Thirty-six patients with septic shock who needed ventilatory support (invasive or noninvasive) and fulfilled inclusion and exclusion criteria during 1-year period from first July 01, 2011, to June 30, 2012, were enrolled in the study [Figure 1]. The criteria for inclusion were fulfillment of two out of four criteria for systemic inflammatory response syndrome, probable or suspected septic etiology, systolic blood pressure $<90 \mathrm{mmHg}$ or mean arterial pressure (MAP) $<70 \mathrm{mmHg}$ despite adequate fluid challenge $(20 \mathrm{ml} / \mathrm{kg}$ of normal saline infused over half hour), and positive pressure ventilation. Criteria for exclusion were pregnancy or other causes of raised intra-abdominal pressure, patients in whom USG could not be done because of poor echo window or dressings, acute coronary syndrome, cardiac dysrhythmias (as a primary diagnosis), congestive heart failure, pulmonary embolism, status asthmaticus, contraindication to central venous catheterization, burn injury, requirement of immediate surgery, and do-not-resuscitate status.

After admission to the ICU, patients were put on a ventilator and central venous catheterization was done. Ventilatory mode and positive end-expiratory pressure applied were recorded for each patient. Echocardiography of patients was done to assess cardiac contractility and to rule out congestive heart failure. Patients were divided into two groups (Groups I and II) depending on the method of fluid resuscitation, and randomization was done by envelope method. Group I patients (18) were resuscitated according to CVP and Group II patients (18) were resuscitated according to IVC CI. CVP was measured by central venous catheters inserted in either subclavian or internal jugular vein with its tip positioned in superior vena cava just proximal to the right atrium. It was measured at zero point which

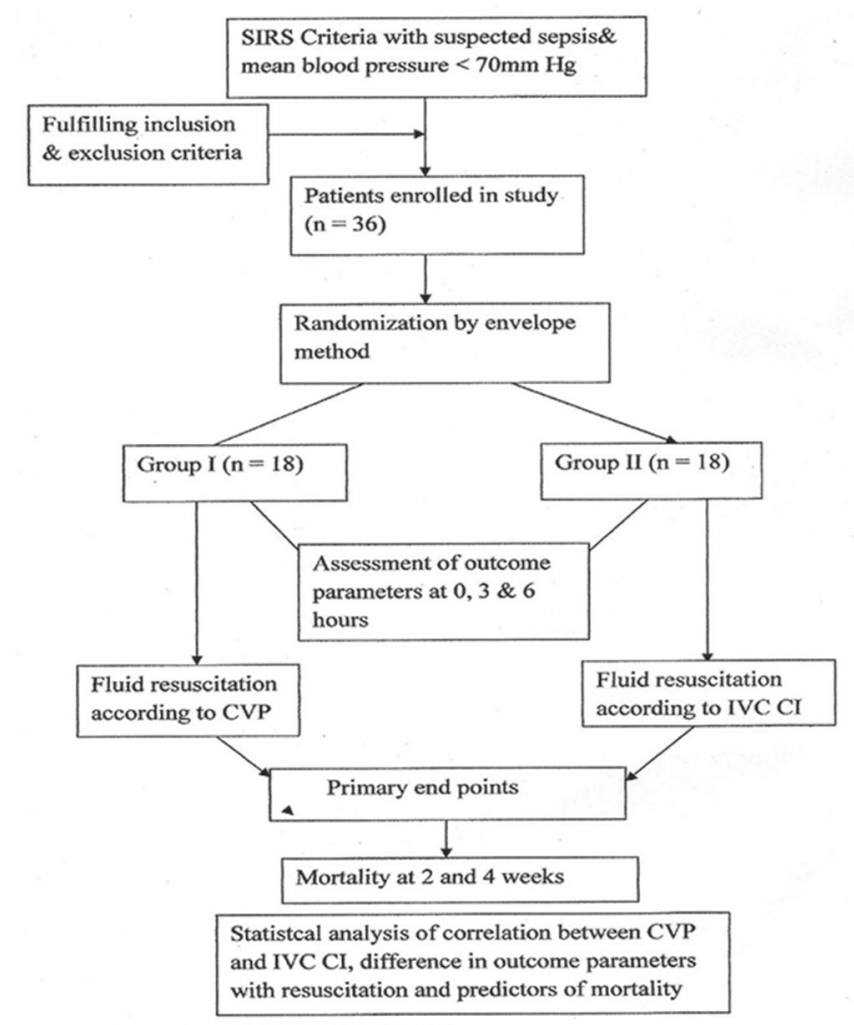

Figure I: Overview of patient enrollment and hemodynamic support 
corresponds with phlebostatic axis. Phlebostatic axis was taken as the line where a coronal plane midway between the back and sternum (in practice, the midaxillary line) intersects a cross-sectional plane through the fourth intercostal space. The CVP was measured in the end-expiratory phase of respiration using a column of saline which was later on converted into $\mathrm{mmHg}$ by dividing it by 1.3. The IVC assessment was made using hand-carried USG unit (Micro Maxx with P17 1-5 MHz phased array probe; Sonosite) with the patient in the supine position using an acoustic window inferior to the xiphoid, angling to the right. The cross-sectional image of the IVC was visualized at the right atrial/hepatic vein/IVC junction and then rotated so that a long axis view of the IVC was obtained. M mode was applied at approximately $1 \mathrm{~cm}$ distal to the IVC-hepatic vein junction where the anterior and posterior walls were clearly visualized. For the sake of simplicity, maximum and minimum diameters were measured in each respiratory cycle. IVC CI was calculated as (maximum diameter on inspiration - minimum diameter on expiration)/minimum diameter on expiration and expressed in percentage [Figure 2]. Video recordings of measurements were later on cross-checked by a senior radiologist (Jyotsna Sen) at our institute.

$$
\mathrm{IVC} C \mathrm{CI}=\mathrm{IVC}_{\mathrm{i}}-\mathrm{IVC}_{\mathrm{e}} / \mathrm{IVC}_{\mathrm{e}}
$$

Both of these variables were recorded in each patient every half-hourly till initial $3 \mathrm{~h}$ and then hourly for next $3 \mathrm{~h}$ or till end-point was reached. Patients were given a fluid bolus $500 \mathrm{ml}$ of crystalloid half-hourly after measuring CVP and IVC CI till target levels of CVP or IVC CI were achieved in respective groups. Vasopressors were started in situations of nonachievement of desired MAP despite reaching end-point CVP or IVC CI values.

Primary end-points were MAP of $\geq 65 \mathrm{mmHg}$ and CVP $>12 \mathrm{mmHg}$ or IVC CI $<20 \%$ in Groups I and II, respectively. Patients were observed till either primary end-points were reached or up to maximum of $6 \mathrm{~h}$. Patients were followed till 4 weeks and survival at 2 and 4 weeks was used as secondary end-point in the study. Outcome variables (pulse rate [PR], MAP, urine output, $\mathrm{pH}$ in arterial blood gas, base deficit, and $\mathrm{ScvO}_{2}$ ) were serially measured in both groups at $0,3 \mathrm{~h}$, and end of the study.

\section{Statistical analysis}

Both descriptive and analytical statistics were used in the study as appropriate. The values were expressed as mean \pm standard deviation. IVC CI values $>100 \%$ were taken as $100 \%$ for the sake of statistical analysis. Correlation between CVP and IVC CI was calculated by Pearson correlation coefficient. Kaplan-Meier estimates were used to graphically represent mortality difference and time to resuscitation between study groups. Paired $t$-test was used to calculate any difference in outcome parameters after fluid resuscitations in both groups. Unpaired $t$-test was used for comparison of intergroup data. $P<0.05$ was considered statistically significant.

\section{Results}

Thirty-six patients of septic shock on a ventilator were randomly divided into two groups based on mode of fluid resuscitation - Group I (CVP) and Group II (IVC $\mathrm{CI})$. There was no significant difference between two groups in baseline characters (age, Acute Physiology and Chronic Health Evaluation [APACHE] score on presentation, PEEP applied, and mean fluid infused) during the study [Table 1]. Etiology of sepsis was found in 24 cases (pneumonia, scrub typhus-induced ALI, abdominal sepsis, and cellulitis in 8, 6, 5, and 5 cases, respectively), while in 12 cases, the cause of sepsis was not found [Table 2].

\begin{tabular}{lccc}
\hline \multicolumn{4}{l}{ Table I: Baseline characteristics of patients } \\
\hline & GROUP I & GROUP II & P \\
\hline Age (yrs) & $44.5 \pm 18.73$ & $37.39 \pm 15.53$ & 0.22 \\
Sex (Female: Male) & $5: 4$ & $4: 5$ & \\
APACHE Score & $20.66 \pm 7.39$ & $21.38 \pm 9.61$ & 0.80 \\
PEEP (cm of H2O) & $6 \pm 1.98$ & $5.68 \pm 0.477$ & 0.498 \\
Amount of fluid (L) & $2.91 \pm 0.60$ & $3.56 \pm 1.42$ & 0.08 \\
Time to resuscitate (hrs) & $4.36 \pm 1.135 \mathrm{hrs}$ & $5.17 \pm 1.294$ & \\
\hline
\end{tabular}

\begin{tabular}{lccc}
\hline \multicolumn{4}{l}{ Table 2: Etiology of sepsis and no. of patients } \\
\hline Etiology & $\begin{array}{c}\text { Total } \\
(\boldsymbol{n}=\mathbf{3 6})\end{array}$ & $\begin{array}{c}\text { Group I } \\
(\boldsymbol{n}=\mathbf{I 8})\end{array}$ & $\begin{array}{c}\text { Group II } \\
(\boldsymbol{n}=\mathbf{I 8})\end{array}$ \\
\hline Pneumonia & 8 & 3 & 5 \\
Scrub typhus induced ALI & 6 & 4 & 2 \\
Abdominal sepsis & 5 & 4 & 1 \\
Cellulitis & 5 & 2 & 3 \\
Undifferentiated causes & 12 & 5 & 7 \\
\hline
\end{tabular}

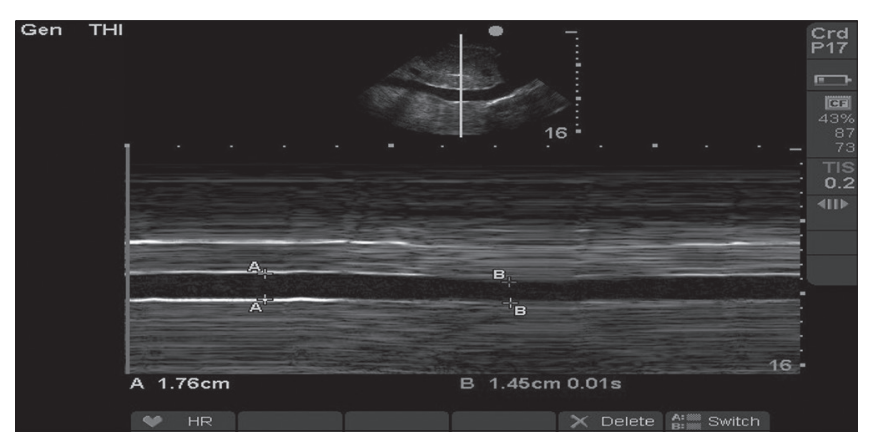

Figure 2: Calculation of inferior vena cava collapsibility index ([A-B]/B) (\%) using ultrasonography 
IVC CI values on admission were very high and variable; to eliminate its effects on results, all values $>100 \%$ were taken to be $100 \%$. With fluid infusion, CVP values increased and IVC CI values decreased in both groups. Correlating CVP and IVC CI among patients, we found moderately negative correlation with a Pearson correlation coefficient -0.626 in total observations [Figure 3]. Coefficient was higher in patients who were resuscitated with IVC CI [Figures 4 and 5] as a tool $(-0.535$ in Group I and -0.709 in Group II). We did subgroup analysis to find the effect of ventilation on correlation (Group A = Invasive [17], Group B = Noninvasive [19]). Correlation coefficient was found to be comparable in both subgroups ( -0.588 in invasive subgroup and -0.562 in noninvasive subgroup).

With resuscitation, $\mathrm{PR}, \mathrm{MAP}, \mathrm{pH}$, and base deficit improved significantly in both groups, but urine output and $\mathrm{ScvO}_{2}$ increased in Group II only [Table 3]. Survival at 2 and 4 weeks was used as a secondary outcome, and there was no significant difference in both groups [Table 4 and Figure 6].

\section{Discussion}

The incidence of sepsis and its complications is increasing despite the evolution of scientific technology. Septic shock and multiple organ dysfunction syndrome still remain a treatment challenge for both primary care physicians and intensivists. The treatment remains mainly supportive, and mortality increases disproportionally with the development of organ failure emphasizing the need for its prevention.

Since the concept of the ICUs in the 1950s, the hemodynamic monitoring has traveled a long way but is still at crossroads. More invasive techniques became popular with time. CVP has been used and

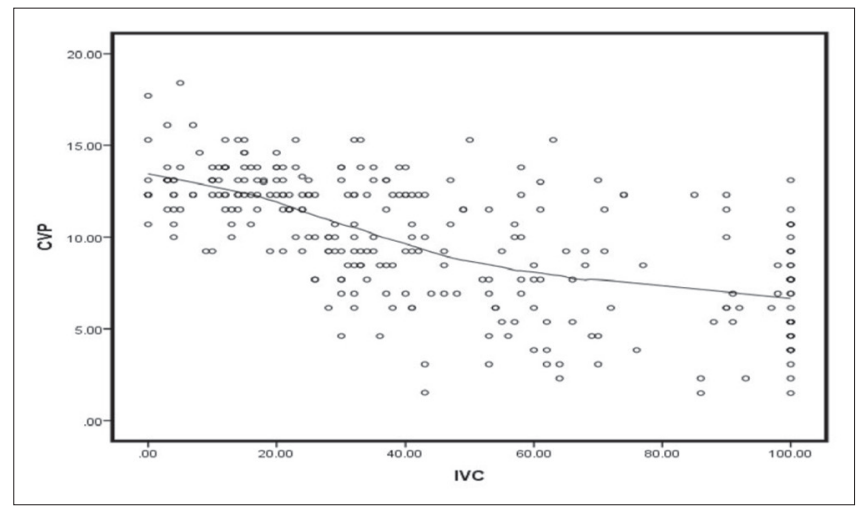

Figure 3: Scatter diagram showing correlation between central venous pressure and inferior vena cava collapsibility index in total observations $\left(r^{2}=-0.636\right)$. Central venous pressure measured in $\mathrm{mmHg}$ and inferior vena cava collapsibility index in \% recommended since long for fluid resuscitation in septic shock. ${ }^{[3,16]}$ However, since CVP is unable to predict exact volume status, it should not be used to make clinical decisions regarding fluid management. ${ }^{[17]}$ In recent times, the pendulum has swung toward noninvasive, simple techniques which are less time consuming. Portable sonographic machines have increased the popularity of variation in IVC dimensions with respiration and fluid infusion in intensive care. Initially, IVC diameter

Table 3 : Comparison of outcome variables at baseline and end of study

\begin{tabular}{|c|c|c|c|}
\hline & Baseline & End of study & $\boldsymbol{P}$ \\
\hline \multicolumn{4}{|l|}{ Pulse rate } \\
\hline Group I & $125.66 \pm 19.90$ & $108.11 \pm 14.16$ & 0.002 \\
\hline Group II & $126.11 \pm 17.55$ & $105.05 \pm 16.59$ & 0.001 \\
\hline$P$ value & 0.944 & 0.556 & \\
\hline \multicolumn{4}{|c|}{ Mean blood pressure $(\mathrm{mm} \mathrm{Hg})$} \\
\hline Group I & $52 \pm 10.52$ & $68.56 \pm 15.88$ & 0.001 \\
\hline Group II & $51.05 \pm 9.09$ & $69.83 \pm 13.12$ & 0.001 \\
\hline$P$ value & 0.772 & 0.795 & \\
\hline \multicolumn{4}{|l|}{$\mathrm{pH}$} \\
\hline Group I & $7.27 \pm 0.10$ & $7.35 \pm 0.11$ & 0.0022 \\
\hline Group II & $7.22 \pm 0.14$ & $7.28 \pm 0.13$ & 0.012 \\
\hline$P$ value & 0.305 & 0.086 & \\
\hline \multicolumn{4}{|l|}{ Base Deficit } \\
\hline Group I & $-9.40 \pm 5.95$ & $-7.6 I \pm 6.33$ & 0.026 \\
\hline Group II & $-13.32 \pm 6.30$ & $-11.29 \pm 6.97$ & 0.030 \\
\hline$P$ value & 0.087 & 0.113 & \\
\hline \multicolumn{4}{|c|}{ UrineOutput (ml/hr) } \\
\hline Group I & $45.83 \pm 38.19$ & $59.59 \pm 46.60$ & 0.410 \\
\hline Group II & $51.44 \pm 54.08$ & $80.94 \pm 80.40$ & 0.022 \\
\hline$P$ value & 0.721 & 0.347 & \\
\hline \multicolumn{4}{|l|}{$\mathrm{ScvO2}(\%)$} \\
\hline Group I & $69.45 \pm 13.21$ & $72.16 \pm 12.34$ & 0.273 \\
\hline Group II & $69.67 \pm 12.04$ & $75.02 \pm 11.24$ & 0.034 \\
\hline$P$ value & 0.966 & 0.479 & \\
\hline
\end{tabular}

Table 4: Survival in both groups at 2 and 4 weeks

\begin{tabular}{lcc}
\hline & Survival at $\mathbf{2}$ weeks $(n)$ & Survival at $\mathbf{4}$ weeks $(n)$ \\
\hline Group I & 9 & 9 \\
Group II & 8 & 7 \\
\hline$n=$ Number of patients.
\end{tabular}

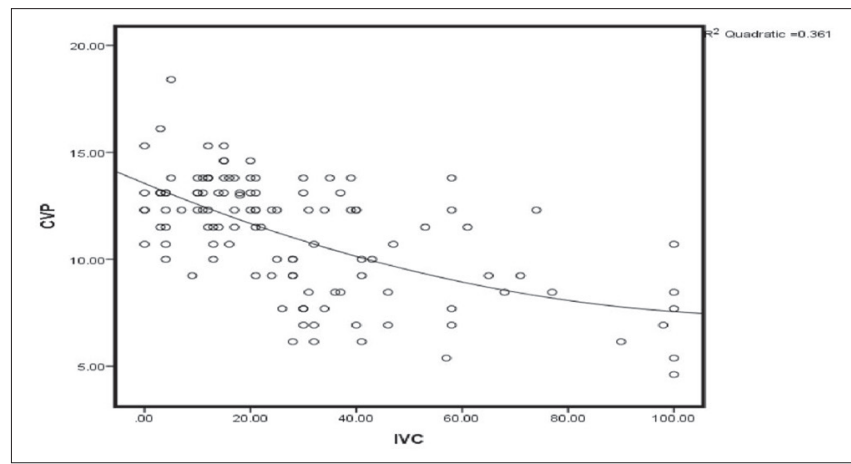

Figure 4: Scatter diagram showing correlation between central venous pressure and inferior vena cava collapsibility index in Group I observations $\left(r^{2}=-0.535\right)$. Central venous pressure measured in $\mathrm{mmHg}$ and inferior vena cava collapsibility index in \% 


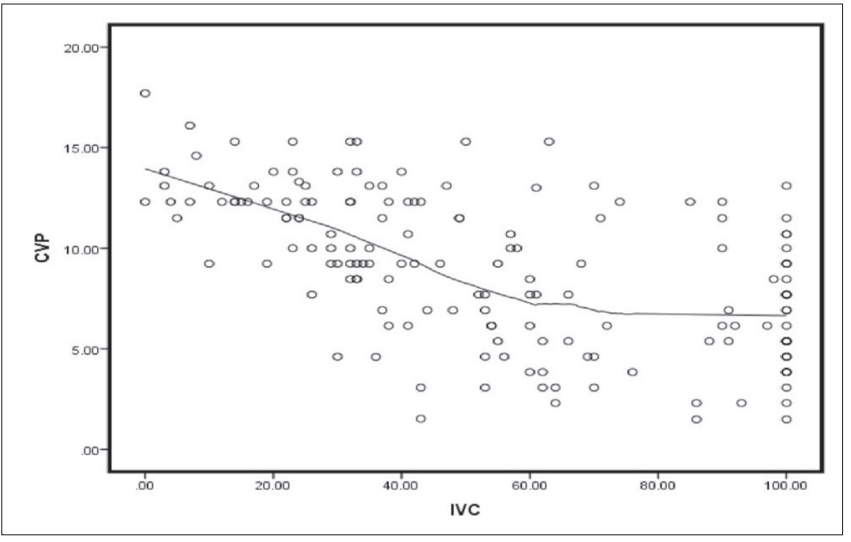

Figure 5: Scatter diagram showing correlation between central venous pressure and inferior vena cava collapsibility index in Group II observations $\left(r^{2}=-0.709\right)$. Central venous pressure measured in $\mathrm{mmHg}$ and inferior vena cava collapsibility index in \%

was explored as a static parameter and was shown to decrease with dehydration indicating the need of fluid resuscitation. ${ }^{[18]}$ As understanding of the physiology of IVC mechanics improved, intensivists started using variability in diameter with respiration. IVC CI, a dynamic tool, has been shown in studies to predict preload responsiveness. ${ }^{[9,10,19]}$

In our study, we used both CVP and IVC CI to evaluate the efficacy of IVC CI and tried to find correlation, if any, between two modalities. The study is in conformity with other studies on the correlation of CVP with IVC $\mathrm{CI}$ on fluid resuscitation. ${ }^{[12,13]}$ With fluid resuscitation, CVP increased and IVC CI decreased and they were negatively correlated $(-0.626)$ with higher correlation in Group II (-0.709 in Group II vs. -0.535 in Group I). This may be partly explained by more fluid infused, although not significantly different, in Group II than Group I ( $3.56 \pm 1.42 \mathrm{~L}$ vs. $2.91 \pm 0.60 \mathrm{~L})$. These findings are comparable to the previous studies. ${ }^{[12]}$ Mode of ventilation had no effect on same (-0.588 in Subgroup I vs. -0.562 in Subgroup II).

With resuscitation, there was no significant difference in outcome variables ( $\mathrm{PR}$, mean blood pressure, $\mathrm{pH}$, and base deficit) and mortality in both groups at baseline and after resuscitation. The difference in urine output may be explained by the fact that more fluid, although not significantly different, was infused in Group II. Target $\mathrm{ScvO}_{2}>70 \%$ was used by River et al. in early goal-directed therapy; ${ }^{[3]}$ however, the incidence of low $\mathrm{ScvO}_{2}$ has been shown to be less in septic patients by other workers. ${ }^{[20-22]} \mathrm{As} \mathrm{ScvO}_{2}$ was $>65 \%$ at baseline in majority of patients, an increase in its value with resuscitation got nullified despite a significant increase in Group II. We had a higher mortality of $52.7 \%$ in our study population with mean APACHE of

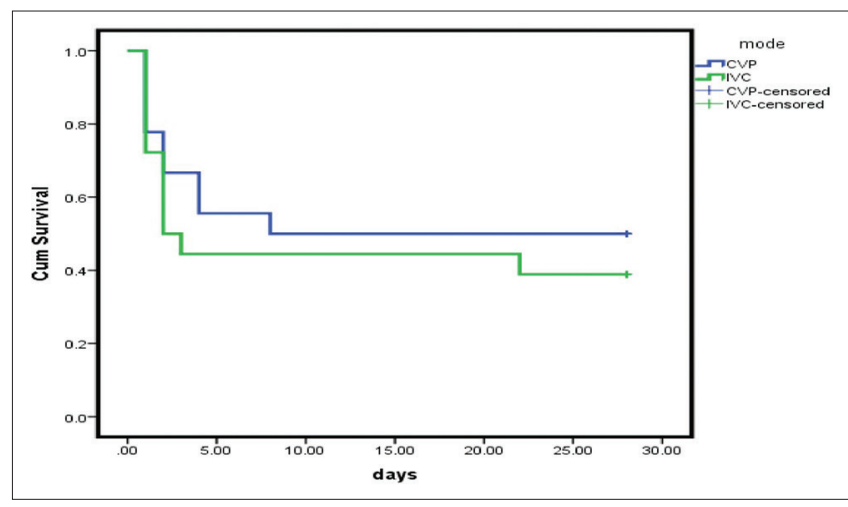

Figure 6: Kaplan-Meier curve showing survival time in both groups

21 (approximately) in both groups, which is in contrast with a predicted mortality of $40 \%$ (corresponding to mean APACHE score of 21). ${ }^{[23]}$

Although the sample size is small, the study demonstrates that measurement of IVC CI is noninferior to CVP for fluid resuscitation in patients of septic shock on ventilation, despite their respective limitations. Therefore, IVC CI can be used to fluid resuscitate patients of septic shock, whenever or wherever there is difficulty or challenges in measuring or interpreting CVP. Measurement of IVC CI with USG, thus, is an important tool in the armamentarium of intensivists to make decisions about fluid resuscitation and its adequacy on patients' bedside.

\section{Limitations of the study}

The wide variation in IVC CI was a major limitation of the study. Poor acoustic window, especially in noninvasively ventilated patients, due to spontaneous respiratory efforts and uncooperativeness of patients was commonly encountered. Therefore, if the operator is inexperienced, one can have false values leading to both over and under estimation. We tried to overcome it by having the values measured by a single operator $(\mathrm{M})$ and later on reviewed by a senior radiologist (Jyotsna Sen). However, still one cannot completely rule out aberrations in measurement on this account.

Outcome parameters might have been influenced by the use of vasopressors. Since we did not study the duration and dosing of vasopressors used, we are not in a position to state their role in reaching end-points.

Lactate levels and clearance were not measured, but rather a surrogate marker of it (base deficit) was calculated in patients. Similarly, although there was an improvement in $\mathrm{ScvO}_{2}$ after resuscitation, its baseline values were above $65 \%$. In addition, the cause for higher mortality among subjects could not be deciphered. 
Finally, due to single center and small sample size, extrapolation of our findings to a large subset of population should be judiciously addressed.

\section{Conclusion}

With fluid infusion, a negative correlation was observed between CVP and IVC CI. Correlation coefficient was more in Group II; however, because of small sample size, we are not in a position to generalize this fact. Both methods resulted in improved resuscitation outcomes, with IVC CI being noninferior to CVP, can be used effectively in fluid resuscitation.

\section{Financial support and sponsorship}

Nil.

\section{Conflicts of interest}

There are no conflicts of interest.

\section{References}

1. Rivers EP, Jaehne AK, Eichhorn-Wharry L, Brown S, Amponsah D. Fluid therapy in septic shock. Curr Opin Crit Care 2010;16:297-308.

2. Dorresteijn MJ, van Eijk LT, Netea MG, Smits P, van der Hoeven JG, Pickkers P. Iso-osmolar prehydration shifts the cytokine response towards a more anti-inflammatory balance in human endotoxemia. J Endotoxin Res 2005;11:287-93

3. Rivers E, Nguyen B, Havstad S, Ressler J, Muzzin A, Knoblich B, et al. Early goal-directed therapy in the treatment of severe sepsis and septic shock. N Engl J Med 2001;345:1368-77.

4. Dellinger RP, Carlet JM, Masur H, Gerlach H, Calandra T, Cohen J, et al. Surviving Sepsis Campaign guidelines for management of severe sepsis and septic shock. Intensive Care Med 2004;30:536-55.

5. Packman MI, Rackow EC. Optimum left heart filling pressure during fluid resuscitation of patients with hypovolemic and septic shock. Crit Care Med 1983;11:165-9.

6. Rosenberg AL, Dechert RE, Park PK, Bartlett RH; NIH NHLBI ARDS Network. Review of a large clinical series: Association of cumulative fluid balance on outcome in acute lung injury: A retrospective review of the ARDSnet tidal volume study cohort. J Intensive Care Med 2009;24:35-46.

7. Marik PE, Monnet X, Teboul JL. Hemodynamic parameters to guide fluid therapy. Ann Intensive Care 2011;1:1

8. Magder S. How to use central venous pressure measurements. Curr
Opin Crit Care 2005;11:264-70.

9. Feissel M, Michard F, Faller JP, Teboul JL. The respiratory variation in inferior vena cava diameter as a guide to fluid therapy. Intensive Care Med 2004;30:1834-7

10. Barbier C, Loubières Y, Schmit C, Hayon J, Ricôme JL, Jardin F, et al. Respiratory changes in inferior vena cava diameter are helpful in predicting fluid responsiveness in ventilated septic patients. Intensive Care Med 2004;30:1740-6.

11. Kircher BJ, Himelman RB, Schiller NB. Noninvasive estimation of right atrial pressure from the inspiratory collapse of the inferior vena cava. Am J Cardiol 1990;66:493-6.

12. Stawicki SP, Braslow BM, Panebianco NL, Kirkpatrick JN, Gracias VH, Hayden GE, et al. Intensivist use of hand-carried ultrasonography to measure IVC collapsibility in estimating intravascular volume status: Correlations with CVP. J Am Coll Surg 2009;209:55-61.

13. Schefold JC, Storm C, Bercker S, Pschowski R, Oppert M, Krüger A, et al. Inferior vena cava diameter correlates with invasive hemodynamic measures in mechanically ventilated Intensive Care Unit patients with sepsis. J Emerg Med 2010;38:632-7.

14. Fields JM, Lee PA, Jenq KY, Mark DG, Panebianco NL, Dean AJ. The interrater reliability of inferior vena cava ultrasound by bedside clinician sonographers in emergency department patients. Acad Emerg Med 2011;18:98-101.

15. Nagdev AD, Merchant RC, Tirado-Gonzalez A, Sisson CA, Murphy MC Emergency department bedside ultrasonographic measurement of the caval index for noninvasive determination of low central venous pressure. Ann Emerg Med 2010;55:290-5

16. Dellinger RP, Levy MM, Carlet JM, Bion J, Parker MM, Jaeschke R, et al. Surviving sepsis campaign guidelines for management of severe sepsis and septic shock. Intensive Care Med 2004;36:296-327.

17. Marik PE, Baram M, Vahid B. Does central venous pressure predict fluid responsiveness? A systematic review of the literature and the tale of seven mares. Chest 2008;134:172-8.

18. Jeffrey RB Jr., Federle MP. The collapsed inferior vena cava: CT evidence of hypovolemia. AJR Am J Roentgenol 1988;150:431-2

19. Jardin F, Vieillard-Baron A. Ultrasonographic examination of the venae cavae. Intensive Care Med 2006;32:203-6.

20. van Beest PA, Hofstra JJ, Schultz MJ, Boerma EC, Spronk PE, Kuiper MA. The incidence of low venous oxygen saturation on admission to the Intensive Care Unit: A multi-center observational study in The Netherlands. Crit Care 2008;12:R33.

21. Krafft P, Steltzer H, Hiesmayr M, Klimscha W, Hammerle AF. Mixed venous oxygen saturation in critically ill septic shock patients. The role of defined events. Chest 1993;103:900-6.

22. Perel A. Bench-to-bedside review: The initial hemodynamic resuscitation of the septic patient according to surviving sepsis campaign guidelines - Does one size fit all? Crit Care 2008;12:2-5.

23. Knaus WA, Draper EA, Wagner DP. APACHE II: A severity of disease classification system. Crit Care Med 1985;13:818-29. 